\title{
Breast Cancer pN3 TNM Finding v6
}

National Cancer Institute

\section{Source}

National Cancer Institute. Breast Cancer pN3 TNM Finding v6. NCI Thesaurus. Code C49004.

Breast cancer with metastasis in 10 or more axillary lymph nodes, or in infraclavicular lymph nodes, or in clinically apparent ipsilateral internal mammary lymph nodes in the presence of 1 or more positive axillary lymph nodes; or in more than 3 axillary lymph nodes with clinically negative microscopic metastasis in internal mammary lymph nodes; or in ipsilateral supraclavicular lymph nodes. (from AJCC 6th Ed.) 